\title{
Association study between a polymorphism at the 3 '-untranslated region of CLOCK gene and attention deficit hyperactivity disorder
}

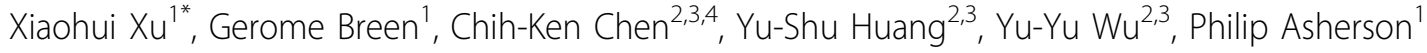

\begin{abstract}
Background: The circadian locomotor output cycles kaput (CLOCK) gene encodes protein regulation circadian rhythm and also plays some roles in neural transmitter systems including the dopamine system. Several lines of evidence implicate a relationship between attention-deficit hyperactivity disorder (ADHD), circadian rythmicity and sleeping disturbances. A recent study has reported that a polymorphism (rs1801260) at the $3^{\prime}$-untranslated region of the CLOCK gene is associated with adult ADHD.

Methods: To investigate the association between the polymorphism (rs1801260) in ADHD, two samples of ADHD probands from the United Kingdom $(n=180)$ and Taiwan $(n=212)$ were genotyped and analysed using withinfamily transmission disequilibrium test (TDT). Bonferroni correction procedures were used to just for multiple comparisons.
\end{abstract}

Results: We found evidence of increased transmission of the T allele of the rs 1801260 polymorphism in Taiwanese samples $(P=0.010)$. There was also evidence of preferential transmission of the T allele of the rs 1801260 polymorphism in combined samples from the Taiwan and UK $(P=0.008)$.

Conclusion: This study provides evidence for the possible involvement of CLOCK in susceptibility to ADHD.

\section{Background}

Attention-deficit hyperactivity disorder (ADHD) is a common and heritable childhood behavioural disorder characterised by developmentally inappropriate levels of hyperactivity, impulsivity and inattentiveness. ADHD is a very complex disease. Polymorphic variants in several genes involved in regulation of dopamine and related neurotransmitter pathways are reported to be associated with ADHD [1]. Some lines of evidence implicate that abnormalities in circadian rhythms is involved in the pathophysiology of mental illness such as mood disorders and schizophrenia [2-6] and sleep manipulations can effect clinical status. A study has reported that adrenal steroid hormones levels change based on circadian rhythms and this may be involved in the development of insomnia and psychiatric disorders [7]. Kamimura et al [8] found that in the wiggling (wag) rat representing

\footnotetext{
* Correspondence: x.xu@iop.kcl.ac.uk

${ }^{1}$ MRC Social, Genetic and Developmental Psychiatry Centre, Institute of

Psychiatry, King's College London, UK

Full list of author information is available at the end of the article
}

an animal model of human ADHD there was abnormal impulsive behavior and a prominent nocturnal hyperactivity when compared to controls.

Various types of sleep disorders have been associated with ADHD [9-14]. In addition, parents of children with ADHD consistently reported disturbance in the sleep of their children $[15,16]$. Recently, several studies gave the evidence of the relationship between sleep disturbance and ADHD [17-20]. Golan et al [17] found that children with ADHD had high prevalence of primary sleep disorders and objective daytime somnolence compared with the control group. Huang et al [18] did systematic study to assess obstructive sleep apnea syndrome (OSAS) and periodic limb movement disorder (PLMD) in children with ADHD compared with a control group. They found sleep disorder in Taiwanese children with ADHD, especially OSA. Sleep problems also were found in adults with ADHD [19,20].

A polymorphism (rs1801260) of CLOCK gene was reported to be associated with evening preference and delayed sleep timing in a Japanese population and it 
suggests that this polymorphism may influence a human behavioural pattern and possibly lead to altered daytime brain performance [21]. However, this finding for eveningness preference was not observed in Caucasian population [22].

In mice study, $C L O C K$ was shown to regulate dopamine neural transmission and the CLOCK mutant mouse showed a pronounced elevation of locomotor activity [23]. Abnormalities in dopaminergic transmission were involved in the pathophysiology of psychiatric disorders [24-26].

The CLOCK gene is located on the long arm of chromosome 4q12 (OMIM *601851, 25 exons in the genomic region spanning $115.138 \mathrm{~kb})$. CLOCK protein is involved in the transcriptional regulation of many circadian output genes and in the core circadian clock $[27,28]$. Up to $10 \%$ of the mammalian transcriptome may be under circadian control, and disruption in the CLOCK locus significantly affects the regulation of transcription $[27,28]$.

Recently several groups did genetic association study between a polymorphism (rs1801260) at the 3 '-untranslated region ( $3^{\prime}$-UTR) of the CLOCK gene and psychiatric disorders [29-33]. However, to our knowledge, only one recent study reported association between the single nucleotide polymorphism (SNP) (rs1801260) in the CLOCK gene and adult ADHD with German background [34].

To provide further clarification of the reported association, in this study we examine the role of this polymorphism in two clinical ADHD samples from the UK and Taiwan.

\section{Methods \\ Subjects}

For the UK sample, DNA was collected from 180 DSMIV ADHD combined subtype probands, from both parents for 116 of the ADHD probands and from the mother alone for 64 of the probands. Ninety-six percent of the sample was male subjects. Cases were recruited from child behaviour clinics in South-East England and referred for assessment if they were thought by experienced clinicians to have a diagnosis of the combined subtype of ADHD under DSM-IV criteria, with no significant Axis I co-morbidity apart from oppositional defiant disorder (ODD) (5.5\%) and conduct disorder (CD) (15.5\%). Intelligence quotient (IQ) was assessed in the majority of the subjects using the Wechsler Intelligence Scale for Children-Third Edition (WISC-III), but for those under 6 years, the Wechsler Preschool and Primary Scale of Intelligence (WPPSI) was applied.

Exclusion criteria included IQ less than 70, neurological disorders or brain damage and autism. Only those individuals fulfilling the recruitment criteria after completion of research assessments were included in the study. The age range was 5-15 years at the time of assessment (mean 10.41, SD 2.34). Parents were interviewed with a modified version of the Child and Adolescent Psychiatric Assessment (CAPA) [35]. Information on ADHD symptoms at school was obtained using the long form of the Conner's questionnaire [36]. The subjects gave their written informed consent and the study was approved by the Ethical committee of King's College London (Reference number: G9814668). All probands were of European-Caucasian origin.

The Taiwanese sample consisted of 212 children with ADHD diagnosed between the ages of 5-15 years (mean 8.96, SD 2.60). Both parents were available for 114 families, only the mother for 59 families and only the father for 39 families. ADHD cases were ascertained from the Child Psychiatric Clinics in the Chang Gung Memorial Hospital in Taipei area, Taiwan. A diagnosis of ADHD was made according to DSM-IV criteria following completion of a standard maternal interview [37] and completion of parent and teacher Conner's revised rating scales [36]. In all $78 \%$ had the combined subtype and $22 \%$ the inattentive subtype of ADHD. With regard to co-morbidity, $4 \%$ had Tourettes syndrome and $4 \%$ oppositional defiant disorder. Autism cases were excluded from the study. No other neurological or behavioural disorders were identified. Eighty-nine percent of the sample was male, 13\% had IQ between 50-69 and $87 \%$ had IQ greater than 69 . Subjects gave their written informed consent, and were approved by the Institutional Review Board, Chang Gung Memorial Hospital, Taiwan (Reference number: 96-0058B).

\section{Genotyping}

The rs1801260 polymorphism was genotyped using the method of PCR and enzyme restriction. Genomic DNA was amplified by using the following primers: 5'TCCAGCAGTTTCATGAGATGC-3'and 5'-GAGGTCATTTCATAGCTGAGC- $3^{\prime}$. The reaction was formed according to the protocol described in the study [34]. The PCR products were incubated overnight at $37^{\circ} \mathrm{C}$ with Bsp12861 (New England Biolabs) and the digested PCR products were run on a $2 \%$ agarose gel containing ethidium bromide. The $\mathrm{T}$ allele is represented by a 221 bp fragment, and the $\mathrm{C}$ allele by a $125 \mathrm{bp}$ and $96 \mathrm{bp}$ fragments.

\section{Statistics}

Family genotype data were analysed using the transmission disequilibrium test (TDT) implemented in UNPHASED program (TDTPHASE) [38]. http://www. mrc-bsu.cam.ac.uk/personal/frank/software/unphased/. The Bonferroni correction was applied for multiple tests and $P<0.025$ was considered to show a statistically significant difference. 


\section{Results}

Population frequencies for the SNP (rs1801260) were estimated from parental genotypes. For the UK and the Taiwanese sample the T-allele frequency of the polymorphism are $73 \%$ and $87 \%$, respectively; the C-allele frequencies are $27 \%$ and $13 \%$, respectively. Allele frequencies of the SNP did not show any significant deviation from those expected according to Hardy-Weinberg equilibrium in either population.

TDT analysis (Table 1) showed that there was evidence of increased transmission of the $\mathrm{T}$ allele of rs1801260 SNP in the Taiwanese sample $\left(\chi^{2}=6.701\right.$, $P=0.010, \mathrm{OR}=2.06)$. No significant association was found between this polymorphism and ADHD in the UK sample $\left(\chi^{2}=2.110, P=0.146\right.$, OR $\left.=1.31\right)$, while combining the two datasets together the $\mathrm{T}$ allele of rs1801260 SNP was significantly over-transmitted to affected probands $\left(\chi^{2}=7.136, P=0.008\right.$, OR $\left.=1.53\right)$. Even after correcting $P$-values using the Bonferroni method for multiple tests a significant association was still found between the $\mathrm{T}$ allele and ADHD.

\section{Discussion}

In this study, we set out to investigate a previously reported finding of association between a single nucleotide polymorphism in the $3^{\prime}$-UTR region of the CLOCK gene (rs1801260) in two independent samples of ADHD probands from UK and Taiwan. We found a significant over-transmission of the $\mathrm{T}$ allele of rs1801260 SNP to ADHD cases in Taiwanese population. No association was observed between this polymorphism and ADHD in the UK sample. We did however find evidence for increased transmission of the $\mathrm{T}$ allele of rs 1801260 in the Taiwanese and UK samples pooled together $(P=0.008)$.

In summary, the rs 1801260 polymorphism has been detected at position 3111 in the CLOCK mRNA 3'UTR region. As for function, this polymorphism was speculated to affect mRNA [39]. The rs1801260 SNP has been reported to have the $C$ allele associated with human diurnal preference [39]. This finding was not replicated in diurnal preference or delayed sleep phase syndrome (DSPS) [22,40]. The T-allele of the rs1801260 polymorphism was suggested as a risk allele for delayed sleep phase syndrome [40]. This polymorphism also has been implicated in a number of psychiatric phenotypes including mood disorders (major depression or bipolar disorder) [29,31,32]. However, no evidence was found that the $C$ allele of the polymorphism influence risk for major depression [41]. Recent study investigated the association between the six tagging SNPs including rs1801260 in CLOCK and schizophrenia and mood disorders in the Japanese population. There was also no association found between rs1801260 SNP and schizophrenia and mood disorders [33]. To our knowledge, only one study has reported that a polymorphism (rs1801260) is associated with adult ADHD [34]. Our study replicates the finding conducted by Kissling et al., 2008 [34], who found a strong significant association $(P=0.001)$ between each of the adult ADHD assessment and the rs1801260 polymorphism with at least one T-mutation being the risk allele in a Caucasians of western European origin and German background. Our data suggests that the T-allele of rs1801260 polymorphism may be a risk allele in the development of ADHD and linked or contributing to a causative polymorphism for ADHD in Taiwanese population.

\section{Conclusion}

In conclusion, in this study we used family-based ADHD data in the UK and Taiwanese population to test for an association between rs1801260 SNP at the 3 '-untranslated region of CLOCK gene and susceptibility to the disorder. Our findings support the notion that genetic variation in the 3'-UTR region of CLOCK gene might be a risk factor in the development of ADHD, particularly in the Taiwanese sample studied. Due to the small sample sizes in our study and only one published data on rs1801260 polymorphism investigated in ADHD, further association studies are needed to confirm or refute the finding. Since the 3'-UTR of CLOCK gene may contain sequences that regulate translation efficiency, mRNA stability, and polyadenylation signals, the rs 1801260 polymorphism may be associated with other functional polymorphisms in $3^{\prime}$-UTR regions, which act as regulatory domains of the gene, and may influence the circadian rhythms $[34,40]$. Therefore more functional polymorphisms of this region should be investigated in other independent studies using larger samples.

Table 1 TDT Analysis of rs1801260 Polymorphism

\begin{tabular}{clrcccc}
\hline & \multicolumn{2}{c}{ UK samples Allele } & \multicolumn{2}{c}{ Taiwanese samples Allele } & \multicolumn{2}{c}{ Combined samples Allele } \\
\hline & T & C & T & C & T & C \\
\hline Transmitted & 61 & 46 & 37 & 18 & 98 & 64 \\
Non-transmitted & 46 & 61 & 18 & 37 & 64 & 98 \\
$\chi^{2}, \mathrm{df}(P$-value $)$ & $2.110,1 \mathrm{df}(0.146)$ & \multicolumn{2}{c}{$6.701,1 \mathrm{df}(0.010)$} & $7.136,1 \mathrm{df}(0.008)$ & \\
\hline
\end{tabular}




\section{Acknowledgements}

This research was funded by The Wellcome Trust (No.079314/4/2/06/2). The study was also supported by the Department of Psychiatry of Chang Gung Memorial Hospital in Taiwan. We wish to thank Dr Keeley Brookes who helped to prepare the UK samples and also the families who took part in this research.

\section{Author details}

MRC Social, Genetic and Developmental Psychiatry Centre, Institute of Psychiatry, King's College London, UK. ${ }^{2}$ Department of Psychiatry, Chang Gung Memorial Hospital, Taiwan. ${ }^{3}$ Chang Gung University School of Medicine, Taiwan. ${ }^{4}$ Division of Mental Health \& Drug Abuse Research, National Health Research Institutes, Taiwan.

\section{Authors' contributions}

$X X$ selected the SNP, performed genotyping, genetic analysis and drafted the manuscript. GB revised the manuscript. CKC, YSH and YYW provided the Taiwanese DNA samples and clinical data. CKC also revised the manuscript. PA supervised the study and revised the paper. All authors contributed to the final critical revision of the manuscript.

\section{Competing interests}

The authors declare that they have no competing interests.

Received: 26 February 2010 Accepted: 12 August 2010 Published: 12 August 2010

\section{References}

1. Asherson P, the IMAGE Consortium: Attention-deficit hyperactivity disorder in the post-genomic era. Eur Child Adolesc Psychiatry 2004, 13:50-70.

2. Barbini B, Benedetti F, Colombo C, Guglielmo E, Campori E, Smeraldi E: Perceived mood and skin body temperature rhythm in depression. Eur Arch Psychiatry Clin Neurosci 1998, 248:157-160.

3. McClung CA: Circadian genes, rhythms and the biology of mood disorders. Pharmacol Ther 2007, 114:222-232.

4. McClung CA: Clock genes and bipolar disorder: implications for therapy. Pharmacogenomics 2007, 8:1097-1100.

5. McClung CA: Role for the Clock gene in bipolar disorder. Cold Spring Harb Symp Quant Biol 2007, 72:637-644.

6. McGrath CL, Glatt SJ, Sklar P, Le-Niculescu H, Kuczenski R, Doyle AE, Biederman J, Mick E, Faraone SV, Niculescu AB, Tsuang MT: Evidence for genetic association of RORB with bipolar disorder. BMC Psychiatry 2009, 9:70.

7. Buckley TM, Schatzberg AF: On the interactions of the hypothalamicpituitary adrenal (HPA) axis and sleep: normal HPA axis activity and circadian rhythm, exemplary sleep disorders. J Clin Endocrinol Metab 2005, 90:3106-3114

8. Kamimura E, Ueno Y, Tanaka S, Sawa H, Yoshioka M, Ueno KI, Inoue T, Li X, Koyama T, Ishikawa R, Nagashima K: New rat model for attention deficit hyperactive disorder (ADHD). Comp Med 2001, 51:245-251.

9. Gruber R, Sadeh A, Raviv A: Instability of sleep patterns in children with attention-deficit/hyperactivity disorder. I Am Acad Child Adolesc Psychiatry 2000, 39:495-501.

10. Chervin RD, Dillon JE, Bassetti C, Ganoczy DA, Pituch KJ: Symptoms of sleep disorders, inattention, and hyperactivity in children. Sleep 1997, 20:1185-1192.

11. Chervin RD, Archbold KH: Hyperactivity and polysomnographic findings in children evaluated for sleep-disordered breathing. Sleep 2001, 24:313-320.

12. Chervin RD, Archbold KH, Dillon JE, Panahi P, Pituch KJ, Dahl RE, Guilleminault C: Inattention, hyperactivity, and symptoms of sleepdisordered breathing. Pediatrics 2002, 109:449-456.

13. O'Brien LM, Holbrook CR, Mervis CB, Klaus CJ, Bruner JL, Raffield TJ, Rutherford J, Mehl RC, Wang M, Tuell A, Hume BC, Gozal D: Sleep and neurobehavioral characteristics of 5- to 7-year-old children with parentally reported symptoms of attention-deficit/hyperactivity disorder. Pediatrics 2003, 111:554-563.

14. O'Brien LM, Ivanenko A, Crabtree VM, Holbrook CR, Bruner JL, Klaus CJ, Gozal D: Sleep disturbances in children with attention deficit hyperactivity disorder. Pediatr Res 2003, 54:237-243.
15. Ross DM, Ross SA: Hyperactivity: Current Issues Research and Theory. New York, Wiley 1982

16. Kaplan BJ, McNicol J, Conte RA, Moghadam HK: Sleep disturbances in preschool aged hyperactive and nonhyperactive children. Pediatrics 1987, 80:839-844.

17. Golan N, Shahar E, Ravid S, Pillar G: Sleep disorders and daytime sleepiness in children with attention-deficit/hyperactive disorder. Sleep 2004, 27:261-266.

18. Huang YS, Chen NH, Li HY, Wu YY, Chao CC, Guilleminault C: Sleep disorders in Taiwanese children with attention deficit/hyperactivity disorder. J Sleep Res 2004, 13:269-277.

19. Philipsen A, Feige B, Hesslinger B, Ebert D, Carl C, Hornyak M, Lieb K, Voderholzer U, Riemann D: Sleep in adults with attention-deficit/ hyperactivity disorder: a controlled polysomnographic study including spectral analysis of the sleep EEG. Sleep 2005, 28:877-884.

20. Sobanski E, Schredl M, Kettler N, Alm B: Sleep in adults with attention deficit hyperactivity disorder (ADHD) before and during treatment with methylphenidate: a controlled polysomnographic study. Sleep 2008, 31:375-381.

21. Mishima K, Tozawa T, Satoh K, Saitoh H, Mishima Y: The 3111T/C polymorphism of hClock is associated with evening preference and delayed sleep timing in a Japanese population sample. Am J Med Genet B Neuropsychiatr Genet 2005, 101-104.

22. Robilliard DL, Archer SN, Arendt J, Lockley SW, Hack LM, English J, Leger D, Smits MG, Williams A, Skene DJ, Von Schantz M: The 3111 Clock gene polymorphism is not associated with sleep and circadian rhythmicity in phenotypically characterized human subjects. I Sleep Res 2002, 11:305-312.

23. McClung CA, Sidiropoulou K, Vitaterna M, Takahashi JS, White FJ, Cooper DC, Nestler EJ: Regulation of dopaminergic transmission and cocaine reward by the Clock gene. Proc Natl Acad Sci USA 2005, 102:9377-9381.

24. Nestler EJ, Carlezon WA Jr: The mesolimbic dopamine reward circuit in depression. Biol Psychiatry 2006, 59:1151-1159.

25. Berk M, Dodd S, Kauer-Sant'anna M, Malhi GS, Bourin M, Kapczinski F, Norman T: Dopamine dysregulation syndrome: implications for a dopamine hypothesis of bipolar disorder. Acta Psychiatr Scand Suppl 2007, 434:41-49.

26. Lang UE, Puls I, Muller DJ, Strutz-Seebohm N, Gallinat J: Molecular mechanisms of schizophrenia. Cell Physiol Biochem 2007, 20:687-702.

27. Oishi K, Miyazaki K, Kadota K, Kikuno R, Nagase T, Atsumi G, Ohkura N, Azama T, Mesaki M, Yukimasa S, Kobayashi H, litaka C, Umehara T, Horikoshi M, Kudo T, Shimizu Y, Yano M, Monden M, Machida K, Matsuda J, Horie S, Todo T, Ishida N: Genome-wide expression analysis of mouse liver reveals CLOCK-regulated circadian output genes. J Biol Chem 2003, 278:41519-41527.

28. Panda S, Antoch MP, Miller BH, Su Al, Schook AB, Straume M, Schultz PG, Kay SA, Takahashi JS, Hogenesch JB: Coordinated transcription of key pathways in the mouse by the circadian clock. Cell 2002, 109:307-320.

29. Serretti A, Benedetti F, Mandelli L, Lorenzi C, Pirovano A, Colombo C, Smeraldi E: Genetic dissection of psychopathological symptoms insomnia in mood disorders and CLOCK gene polymorphism. Am J Med Genet B Neuropsychiatr Genet 2003, 121B:35-38.

30. Takao T, Tachikawa H, Kawanishi Y, Mizukami K, Asada T: CLOCK gene T3111C polymorphism is associated with Japanese schizophrenics: a preliminary study. Eur Neuropsychopharmacol 2007, 17:273-276.

31. Benedetti F, Dallaspezia S, Fulgosi MC, Lorenzi C, Serretti A, Barbini B, Colombo C, Smeraldi E: Actimetric evidence that CLOCK 3111 T/C SNP influences sleep and activity patterns in patients affected by bipolar depression. Am J Med Genet B Neuropsychiatr Genet 2007, 144B:631-635.

32. Benedetti F, Radaelli D, Bernasconi A, Dallaspezia S, Falini A, Scotti G, Lorenzi C, Colombo C, Smeraldi E: Clock genes beyond the clock: CLOCK genotype biases neural correlates of moral valence decision in depressed patients. Genes Brain Behav 2008, 7:20-25.

33. Kishi T, Kitajima T, Ikeda M, Yamanouchi Y, Kinoshita Y, Kawashima $K$, Okochi T, Okumura T, Tsunoka T, Inada T, Ozaki N, Iwata N: Association study of clock gene (CLOCK) and schizophrenia and mood disorders in the Japanese population. Eur Arch Psychiatry Clin Neurosci 2009, 259:293-297.

34. Kissling C, Retz W, Wiemann S, Coogan AN, Clement RM, Hünnerkopf R, Conner AC, Freitag CM, Rösler M, Thome J: A polymorphism at the 3'- 
untranslated region of the CLOCK gene is associated with adult attention-deficit hyperactivity disorder. Am J Med Genet B Neuropsychiatr Genet 2008, 147:333-338.

35. Angold A, Prendergast M, Cox A, Harrington R, Simonoff E, Rutter M: The Child and Adolescent Psychiatric Assessment (CAPA). Psychol Med 1995, 25(4):739-753.

36. Conners CK: The Conners Rating Scales: Instruments for Assessments of Childhood Psychopathology. Duke University: Durham, USA 1995.

37. Kaufman J, Birmaher B, Brent D, Rao U, Flynn C, Moneci P, Williamson D, Ryan N: Schedule for affective disorders and schizophrenia for schoolage children-present and lifetime version (K-SADS-PL): initial reliability and validity data. J Am Acad Child Adolesc Psychiatry 1997, 36:980-988.

38. Dudbridge F: Pedigree disequilibrium tests for multilocus haplotypes. Genet Epidemiol 2003, 25:115-121.

39. Katzenberg D, Young T, Finn L, Lin L, King DP, Takahashi JS, Mignot E: A CLOCK polymorphism associated with human diurnal preference. Sleep 1998, 21:569-576.

40. Iwase T, Kajimura N, Uchiyama M, Ebisawa T, Yoshimura K, Kamei Y, Shibui K, Kim K, Kudo Y, Katoh M, Watanabe T, Nakajima T, Ozeki Y, Sugishita M, Hori T, Ikeda M, Toyoshima R, Inoue Y, Yamada N, Mishima K, Nomura M, Ozaki N, Okawa M, Takahashi K, Yamauchi T: Mutation screening of the human Clock gene in circadian rhythm sleep disorders. Psychiatry Res 2002, 109:121-128.

41. Desan PH, Oren DA, Malison R, Price LH, Rosenbaum J, Smoller J, Charney DS, Gelernter J: Genetic polymorphism at the CLOCK gene locus and major depression. Am J Med Genet 2000, 96:418-421.

doi:10.1186/1744-9081-6-48

Cite this article as: Xu et al: Association study between a polymorphism at the 3'-untranslated region of CLOCK gene and attention deficit hyperactivity disorder. Behavioral and Brain Functions 2010 6:48.

\section{Submit your next manuscript to BioMed Central and take full advantage of:}

- Convenient online submission

- Thorough peer review

- No space constraints or color figure charges

- Immediate publication on acceptance

- Inclusion in PubMed, CAS, Scopus and Google Scholar

- Research which is freely available for redistribution

Submit your manuscript at www.biomedcentral.com/submit 